\title{
RESENHA
}

\section{RIVER CHANNEL RESTORATION: GUIDING PRINCIPLES FOR SUSTAINABLE PROJECTS}

\author{
ANDREW BROOKES e E. DOUGLAS SHIELDS JR, (orgs.) \\ England: John Wiley \& Sons, 1996
}

A prática da recuperação de canais fluviais (restoration) está em fase de crescimento e a participação dos processos geomorfológicos, em conjunto com os processos hidrológicos e ecológicos, é determinante para caracterizar o ecossistema aquático. Não há dúvidas de que a recuperação dos canais representa mais um importante esforço para melhorar a qualidade e a integridade dos sistemas aquáticos.

Essa prática coincide com o recente crescimento da melhoria dos sistemas que têm sido impactados pela tentativa de controlar sua função natural de navegação, produção de energia, irrigação ou controle de inundação. Esses processos afetam a preservação da biodiversidade e manutenção dos limites de habitats requeridos para sustentar a diversa manutenção da flora e fauna que caracterizam os canais dos rios e suas formas associadas.

A conservação dos sistemas fluviais requer, portanto, ativa gestão, antes que a degradação irreversível tenha se instalado e, nesse contexto, o livro River Channel Restoration procura fornecer um entendimento dos princípios fundamentais que podem guiar os gestores na tarefa de realizar a recuperação sustentável dos ecossistemas aquáticos.

Com uma coleção de 14 capítulos os autores apresentam um livro fundamental que integra revisões sobre as questões teóricas apresentando o estado da arte com contribuições dos principais especialistas europeus e norte-americanos. Um valor adicional deste livro refere-se à ênfase no guia prático para os gestores dos rios, 
com discussões e análises de estudos de caso. O texto está muito bem ilustrado com diagramas, tabelas e fotos.

A obra está dividida em três partes. A primeira analisa com detalhe os fatores abióticos que podem ser considerados. A segunda parte detém-se especificamente na necessidade potencial da visão integradora e na terceira parte revê experiências vivenciadas em várias partes do mundo.

O livro é um importante guia para as avaliações das experiências que vêm sendo realizadas no Brasil sobre a recuperação dos canais, em especial as realizadas nas cidades de Manaus, Rio Branco e Goiânia, entre outras. Em nosso país a recuperação cênica, que considera somente os aspectos das margens dos rios tem sido a mais utilizada em detrimento de uma recuperação lótica.

Sandra Cunha 